\title{
Dairy consumption and CVD: a systematic review and meta-analysis
}

\author{
Dominik D. Alexander ${ }^{1,2 *}$, Lauren C. Bylsma ${ }^{1}$, Ashley J. Vargas ${ }^{1}$, Sarah S. Cohen ${ }^{1}$, Abigail Doucette ${ }^{1}$, \\ Muhima Mohamed ${ }^{3}$, Sarah R. Irvin ${ }^{5}$, Paula E. Miller ${ }^{1}$, Heather Watson ${ }^{4}$ and Jon P. Fryzek ${ }^{5}$ \\ ${ }^{1}$ EpidStat Institute, 2100 Commonwealth Blvd, Suite 203, Ann Arbor, MI 48105 USA \\ ${ }^{2}$ EpidStat Institute, 16323 38th Drive SE, Bothell, WA 98012, USA \\ ${ }^{3}$ Exponent Inc., Health Sciences, Bellevue, WA, USA \\ ${ }^{4}$ EpidStat Institute, 149 Commonwealth Drive, Menlo Park, CA 94025, USA \\ ${ }^{5}$ EpidStat Institute, Johns Hopkins Campus, 9601 Medical Center Drive, Rockville, MD 20850, USA
}

(Submitted 5 February 2015 - Final revision received 21 October 2015 - Accepted 9 November 2015)

\section{Abstract}

Inverse associations between dairy consumption and CVD have been reported in several epidemiological studies. Our objective was to conduct a meta-analysis of prospective cohort studies of dairy intake and CVD. A comprehensive literature search was conducted to identify studies that reported risk estimates for total dairy intake, individual dairy products, low/full-fat dairy intake, Ca from dairy sources and CVD, CHD and stroke. Random-effects meta-analyses were used to generate summary relative risk estimates (SRRE) for high $v$. low intake and stratified intake dose-response analyses. Additional dose-response analyses were performed. Heterogeneity was examined in sub-group and sensitivity analyses. In total, thirty-one unique cohort studies were identified and included in the meta-analysis. Several statistically significant SRRE below 1.0 were observed, namely for total dairy intake and stroke (SRRE $=0.91 ; 95 \%$ CI $0 \cdot 83$, 0.99), cheese intake and CHD $(\mathrm{SRRE}=0.82 ; 95 \% \mathrm{CI} 0.72,0.93)$ and stroke $(\mathrm{SRRE}=0.87 ; 95 \% \mathrm{CI} 0.77,0.99)$, and Ca from dairy sources and stroke $(\mathrm{SRRE}=0.69 ; 95 \% \mathrm{CI} 0.60$, 0.81). However, there was little evidence for inverse dose-response relationships between the dairy variables and CHD and stroke after adjusting for within-study covariance. The results of this meta-analysis of prospective cohort studies have shown that dairy consumption may be associated with reduced risks of CVD, although additional data are needed to more comprehensively examine potential dose-response patterns.

\section{Key words: Meta-analyses: Epidemiology: Dairy products: Milk: CVD: Stroke: CHD}

The global health burden of CVD, including CHD and stroke, is immense, as CVD is the leading cause of mortality worldwide, accounting for approximately $30 \%$ of all deaths ${ }^{(1)}$. CVD is the leading cause of death in Europe, accounting for over four million deaths each year ${ }^{(2)}$. In Europe, CHD and stroke account for the first and second most common causes of death, with an estimated 1.8 million and almost 1.1 million deaths each year, respectively, although both of these rates have been declining in most European countries from 1990 to $2010^{(2)}$. CVD is the leading cause of death in the USA, and it is responsible for approximately 600000-800000 deaths/annum, or one out of every three to four deaths ${ }^{(3-6)}$. In the USA, the relative rate of CVD and stroke declined significantly from 2000 to 2010, but each year approximately 795000 people experience a new or recurrent stroke ${ }^{(3,4)}$. The most common type of heart disease in the USA is coronary artery disease, which is responsible for 380000 deaths annually ${ }^{(3,4,6)}$

Several factors, including modifiable lifestyle factors, have been identified that increase or decrease the risk of CVD. In a recent paper regarding trends in CVD, the population attributable fraction was reported to be $40.6 \%$ for high blood pressure on CVD mortality, and lower yet still meaningful attributable fractions were observed for smoking, poor diet, insufficient physical activity and abnormal blood glucose levels ${ }^{(7)}$. On the basis of a 2014 joint report from the American Heart Association and the Centers for Disease Control and Prevention, National Institutes of Health, and other governmental agencies, it was suggested that the declining trend in CVD and stroke rates are because of enhanced and proactive CVD risk factor control interventions, such as hypertension control efforts that were initiated over the past few decades ${ }^{(3,4)}$. Other interventions have included efforts to control diabetes mellitus and high cholesterol and smoking cessation programs ${ }^{(3,4,8)}$. Despite these successful efforts, CVD remains the most significant public health burden of disease in many countries, including Europe and the USA.

Several previous studies and meta-analyses have examined the relationship between dairy intake and CVD and related

Abbreviations: GLST, generalised least-squares trend; ICD, International Classification of Diseases; RR, relative risk; SRRE, summary relative risk estimate. 
outcomes, with inverse associations generally observed ${ }^{(9-13)}$. Most recently, Qin et al. ${ }^{(14)}$ conducted a meta-analysis of dairy consumption and CVD and found statistically significant inverse associations for dairy consumption and total CVD and stroke, cheese intake and stroke and CHD, and low-fat dairy intake and stroke. However, the authors did not perform any doseresponse analyses, and used broad categories of dairy variables and outcome variables in their analyses.

Given the accumulating epidemiological data on the relationship between dairy intake and CVD and CVD-related outcomes, the objective of the present study was to conduct a comprehensive meta-analysis of prospective cohort studies that updates the state of the epidemiological science. The specific aims were as follows: (i) to estimate summary associations between total dairy intake and specific dairy products and CVD, CHD and stroke; (ii) to conduct sub-group and sensitivity analyses by descriptive study characteristics to identify potential sources of heterogeneity and to evaluate patterns of associations; (iii) evaluate dose-response using categorical intake analyses and linear splines; and (iv) to evaluate the potential for publication bias.

\section{Methods}

We followed the preferred reporting items for systematic reviews and meta-analyses (PRISMA) guidelines for this systematic review and meta-analysis ${ }^{(15)}$. The PRISMA checklist has been submitted to the journal as an attachment to this manuscript. The twenty-seven checklist items pertain to the content of a systematic review and meta-analysis, which includes the title, abstract, methods, results, discussion and funding

\section{Literature search and study identification}

A comprehensive literature search was conducted using PubMed to identify prospective cohort studies that investigated dairy consumption and CVD. Additional literature searches using Embase were performed as well. The exposures of interest included total dairy intake, specific dairy products (e.g. milk, cheese, yoghurt), Ca from dairy products (reported as an analytical variable in the individual studies) and low- and full-fat dairy intake. The outcomes of interest included CVD, CHD and stroke. Thus, a comprehensive literature search through March 2015, with no lower date limit, was conducted. The search included the following terms: ('dairy products' [MeSH] OR 'dairy calcium' OR milk OR yogurt OR cheese OR cream OR butter OR dairy) AND ('heart diseases' [MeSH] OR 'vascular diseases' [MeSH] OR 'death, sudden' [MeSH] OR 'heart disease' OR 'stroke' OR 'cerebrovascular accident' OR 'sudden death' OR 'cardiac arrest' OR 'cardiovascular disease' OR 'coronary artery disease' OR 'heart failure' OR 'cardiovascular mortality' OR 'coronary death' OR CHD OR CVD OR 'cardiac death' OR 'myocardial infarction' OR angina) AND ('randomized controlled trial' [PT] OR 'cohort studies' [MeSH] OR cohort OR RCT OR 'randomized controlled trial') NOT ('animal experimentation' [MeSH] OR 'case reports' [PT] OR 'cross-sectional studies'
[MeSH] OR 'case-control studies' [MeSH] OR editorial [PT] OR letter [PT] OR 'in vitro' [PT] OR comment [PT] OR review [PT] OR 'review literature as topic' $[\mathrm{MeSH}])$. Supplementary literature searches included screening of reference lists from all relevant studies, pertinent review articles and meta-analyses. All search results were screened by two authors.

To be included in the meta-analysis, a published study had to meet the following criteria: (1) prospective design; (2) adult human population; (3) English language; and (4) provide risk estimates and measures of variance for dairy intake and CVD. Total dairy intake, individual dairy products (e.g. yoghurt or milk) and dairy-derived $\mathrm{Ca}$ intakes were eligible exposure variables in each study. We did not include studies of dietary patterns, such as 'dairy product patterns' and CVD outcomes. Total CVD (fatal or non-fatal), CHD (fatal or non-fatal) and stroke (fatal or non-fatal, including specific types of stroke) were included as outcomes. The literature search flow diagram is shown in Fig. 1.

\section{Data extraction and statistical analysis}

The following data were extracted from each study: first author, publication year, cohort name, year of diet assessment, geographic location, sample size, years of follow-up, population demographic characteristics, diet assessment method, dairy exposure and definitions, CVD and related outcomes (including the author-based definitions and International Classification of Diseases (ICD) codes), median or range of intakes across quantiles, relative risk (RR) and 95\% CI in each quantile of intake and statistical adjustments. If more than one article from the same study population was published, data from the publication with the longest follow-up were extracted. If one cohort had more than one publication but each publication presented results from at least one unique analysis (e.g. the Japan Collaborative Cohort Study), data were extracted for all unique analyses. Two investigators ascertained individual study information independently.

Random-effects models were used to calculate summary relative risk estimates (SRRE), 95\% CI and corresponding $P$ values for heterogeneity. The study weights were equal to the inverse of the variance of each study's effect estimate according to the methodology developed by DerSimonian and Laird ${ }^{(16)}$. Relative risks comparing the highest with the lowest category of intake were combined across all studies to produce the summary associations. When both crude and multivariate adjusted RR were provided, we extracted the most fully adjusted risk estimate. Primary meta-analysis models were created for total dairy consumption, specific dairy products (milk, cheese and yoghurt), full-fat and low-fat dairy intake, Ca from dairy sources and total CVD, CHD and stroke. We made an effort to not mix and match different dairy products together, and we harmonised our outcome classifications based on similar disease rubrics. To be included in the total dairy intake analyses, dairy intake had to be reported in the individual studies as a composite variable representing dairy intake from all sources. For example, if data for total milk only was reported in a study, these data would go into the milk only analyses. Similarly, total CVD was required to be reported as a composite of all CVD outcomes rather than specific outcomes, such as 


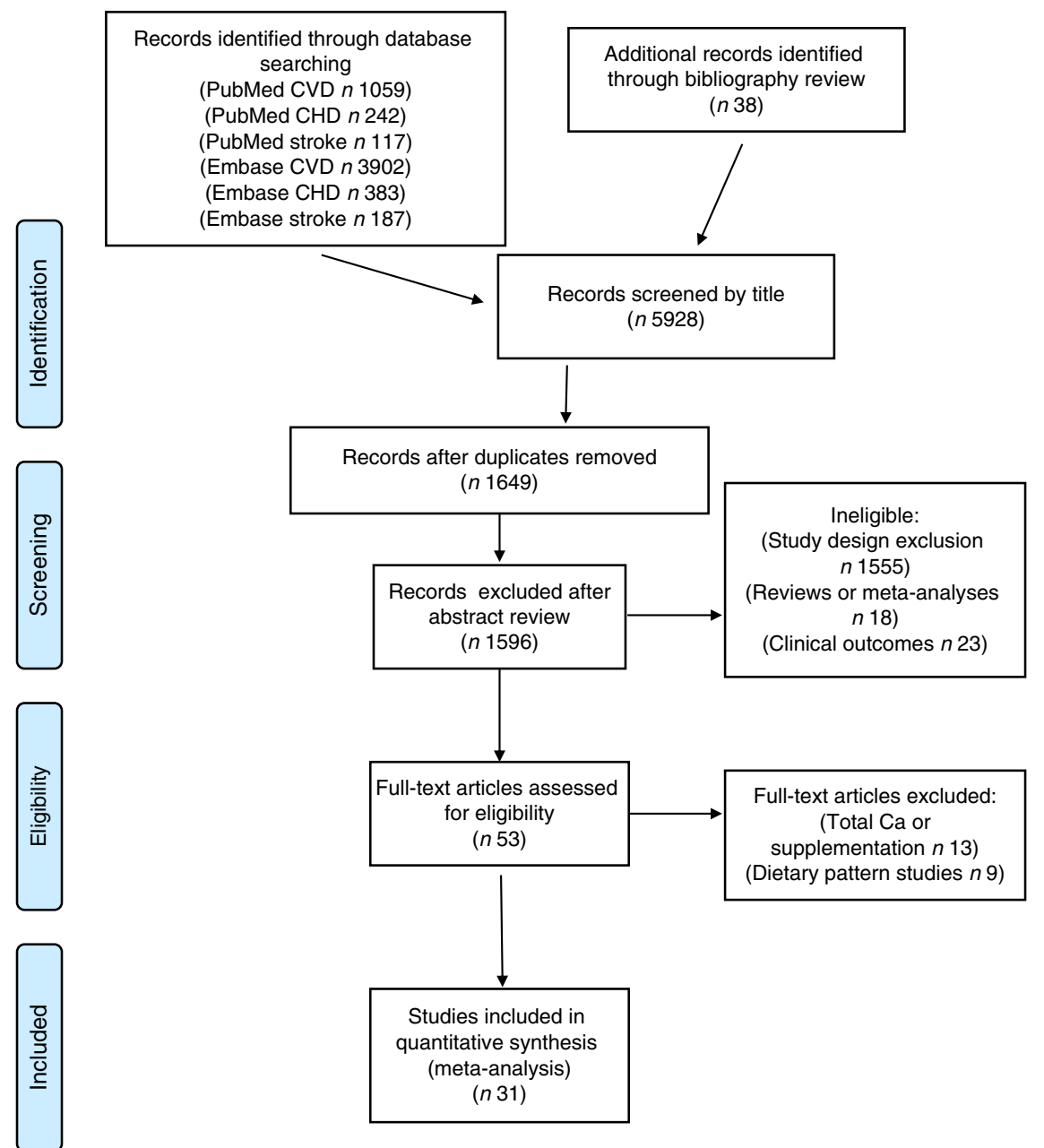

Fig. 1. Flow chart of the article screening process ${ }^{(15)}$. For more information, visit www.prisma-statement.org

stroke. Thus, we generated meta-analyses based on specific dairy products, such as milk, and specific outcomes, such as CHD or stroke. Sub-group and sensitivity analyses were conducted to evaluate variability by descriptive study factors and to identify potential sources of heterogeneity. Sub-group models were generated when three or more studies provided relevant data to be meta-analysed. One-study-removed sensitivity analyses were conducted to determine the relative influence each study had on the overall model.

We used two different approaches to estimate any possible dose-response patterns. First, we created meta-analysis models based on stratified categories of dairy intake. This involved extracting all available relative risk and 95\% CI data from all intake categories from all prospective cohort studies. Then, RR were combined and meta-analysed according to their intake category. Using this approach, no assumptions were made concerning linearity, and this method allows for the evaluation of risk based on varying levels of dairy consumption. However, this method does not account for within-study intake correlations. Thus, in our second dose-response approach, we conducted linear trend analyses that account for correlated intakes within studies. Specifically, when events and the number of person-years per category of dairy intake were available, or when they could be extrapolated using the methods described by Aune ${ }^{(17)}$, they were used as input into the two-stage fixedeffects model described by Greenland and Longnecker ${ }^{(18)}$ using the Stata command for generalised least-squares trend (GLST) ${ }^{(19,20)}$ to estimate a summary risk ratio per dose of dairy intake. Linear splines were used to model dose effects where knots were placed at the same cut-off points for each dairy category described in this manuscript. Tests for linearity were conducted to determine whether splines improved GLST model fit. A limitation to this method is that the number of cases and person-years for each intake category are required for analytical inclusion, and not all studies reported this information. As a result, more data points were included in the stratified intake analyses, although the GLST analyses are able to account for within-study covariance. In addition, we ran restricted cubic spline GLST analyses; however, these models did not perform better than the linear GLST models. Thus, we reported results from the linear spline analyses.

Most studies reported results in terms of servings per $\mathrm{d}$ for total dairy intake, milk and cheese, although some studies 
reported results based on $\mathrm{g} / \mathrm{d}$ metrics. Therefore, we harmonised units by converting $\mathrm{g} / \mathrm{d}$ to servings in these instances. To do this, we reviewed the distribution of intake in the individual studies and we also reviewed the United States Department of Agriculture National Nutrient Database ${ }^{(21)}$. A single serving of milk was considered as $244 \mathrm{~g}$, and a serving of cheese was considered as $35 \mathrm{~g}$. We were not able to convert grams of total dairy intake to servings because total dairy intake represents variable products (e.g. cheese, milk, yoghurt) with variable conversions. Some studies reported data for dairy intake and $\mathrm{CVD} / \mathrm{CHD} /$ stroke per standard deviation of the mean in $\mathrm{g} / \mathrm{d}$ or by unit increase in component score ${ }^{(22-24)}$; thus, data from these studies were used in our dose-response analyses only.

Statistical heterogeneity was assessed using the Cochran's $Q$ test and $I^{2}$ statistic, which indicates the percentage of variation attributable to between-study heterogeneity ${ }^{(25)}$. The presence of publication bias was assessed visually by examining a funnel plot measuring the standard error as a function of effect size, as well as performing Egger's regression method and the Duval and Tweedie imputation method ${ }^{(26)}$. We generated forest plots for models of total dairy intake and CVD, CHD and stroke. All statistical analyses were performed using Comprehensive Meta-Analysis Software (version 3.3.070; Biostat) and Stata (version 14).

\section{Results}

A total of thirty-one unique prospective cohort studies were included in the meta-analysis (Table 1$)^{(22-24,27-54)}$. Studies were published between 1996 and 2015 with baseline dietary assessment periods ranging between 1965 and 2001. Over one million participants were analysed for CVD or CVD-related outcomes across the studies. In the majority of studies, ICD codes for the CVD outcomes were provided. For CVD, ICD-9 codes 390-459 and ICD-10 codes 100-199 were reported; for CHD, ICD-9 codes 400-414, 427.5, 429.2, 798.1, 798.2, 798.9 and ICD-10 codes 120-125 were reported; and for stroke, ICD-9 codes 430-439 and ICD-10 codes 160-169 were reported. Follow-up periods ranged between 5 and 26 years, with most studies following up participants for 10-20 years. Studies were conducted in a variety of countries, including the USA, Europe, the Nordic countries, Australia and Japan. Dairy intake information was ascertained via FFQ, and while some studies reported results data for total dairy intake other studies reported data for specific products, such as milk, or specific constituents, such as dairy $\mathrm{Ca}$. We made a concerted effort to make our analytical models as homogeneous as possible in terms of dairy exposure and CVD outcomes. Thus, if a study-specific variable was recorded as 'total milk', results data for this variable were not included in the meta-analysis model of individual study variable labelled as 'total dairy intake'. Midpoint values of dairy servings per $\mathrm{d}$ ranged between $0 \cdot 1$ and 9.3 for total dairy intake, 0.3 and 3.5 for milk and 0.3 and 6.0 for cheese. However, the greatest proportion of intake categories ranged between 1 and 3 servings/d for total dairy intake, and between 1 and 2 servings/d for milk and cheese.

\section{Meta-analysis results}

The meta-analysis results are summarised in Table 2 .

Total dairy intake. Only four cohort studies reported a composite 'total dairy intake' variable with specific results data for a composite 'total CVD' variable ${ }^{(32,39,44,51)}$. Meta-analysis of these studies resulted in an SRRE of 0.88 (95\% CI $0.75,1.04)$ with moderate heterogeneity $\left(P_{\mathrm{H}}=0.076, I^{2}=52.7\right)$ (Fig. 2). There was no statistical evidence of publication bias in this model $(P=0 \cdot 39)$.

The SRRE based on the meta-analysis of seven studies of total dairy intake and total CHD was 0.91 (95\% CI $0.80,1.04$ ) (Fig. 3) $(30,33,36,39,44,48,50)$, with significant heterogeneity $\left(P_{\mathrm{H}}=\right.$ $0 \cdot 038, I^{2}=52 \cdot 8$ ) that was explained, in part, by descriptive study factors. Sub-group analysis of the three US studies showed no association between total dairy intake and risk of total CHD (SRRE $=0.99 ; 95 \%$ CI $0.92,1.07)^{(30,33,36)}$. The remaining four studies were all conducted among study participants from different countries. Four studies evaluated total dairy intake and CHD risk among women, resulting in an SRRE of $0.86(95 \% \text { CI } 0.71,1.05)^{(30,33,39,48)}$. Only one study reported results data specifically for men. Meta-analysis of studies with follow-up periods of 15 years or less resulted in a statistically significant SRRE of 0.81 (95\% CI 0.71, 0.93) with little heterogeneity $\left(P_{\mathrm{H}}=0.549, I^{2}=0 \cdot 0\right)^{(33,44,48,50)}$, but no association $(\mathrm{SRRE}=1.00)$ was found in the analysis of studies with greater than 15 years of follow-up ${ }^{(30,36,39)}$. There was modest variability between full-fat dairy intake (SRRE $=1.05 ; 95 \%$ CI $0.93,1 \cdot 19)$ and low-fat dairy intake (SRRE $=0.90 ; 95 \%$ CI $0.82,0.98$ ) on CHD risk $^{(30,36,44,50)}$. We stratified total dairy intake into three categories of intake but no patterns of associations based on levels of intake were apparent, with SRRE of 0.88, 0.93 and 0.86, based on $<1.5$ servings, $1.5-3$ servings and $>3$ servings, respectively. Furthermore, the GLST procedure did not show a pattern of linear dose-response (RR per serving $=1 \cdot 00 ; 95 \% \mathrm{CI}$ $0.98,1.01)$, and the use of linear spline modelling did not provide evidence of a non-linear dose-response $\left(\chi^{2} P\right.$ value $=$ $0 \cdot 11)$. No evidence of publication bias was detected in the model of total dairy intake and $\operatorname{CHD}(P=0 \cdot 41)$.

Intake of total dairy intake was associated significantly and inversely with total stroke $(\mathrm{SRRE}=0.91 ; 95 \% \mathrm{CI}$ $0.83,0.99)$ with moderate heterogeneity $\left(P_{\mathrm{H}}=0.072 ; I^{2}=44.5\right)$ (Fig. 4) $)^{(31,39-41,43,44,49)}$. The heterogeneity was explained, in part, by certain study characteristics, namely duration of followup, fat content and dose. Meta-analysis of studies that followed up participants longer than 15 years resulted in an SRRE of $0 \cdot 88$ (95\% CI 0.82, 0.95, $\left.P_{\mathrm{H}}=0.492, I^{2}=0 \cdot 0\right)$. Adding Louie et al. ${ }^{(44)}$ to this model (the mean follow-up in this study was 15 years) did not change the SRRE but made the model more homogeneous $\left(P_{\mathrm{H}}=0.614, I^{2}=0 \cdot 00\right)$. Both full-fat dairy intake $(\mathrm{SRRE}=0.91 ; 95 \% \mathrm{CI} 0.84,0.99)$ and low-fat dairy intake (SRRE $=0.90 ; 95 \%$ CI 0.83, 0.96) were associated inversely and significantly with stroke, with no heterogeneity found in each model. Less than 1.5 servings and 1.5 or more servings of total dairy intake were associated inversely and statistically significantly with total stroke. We were unable to conduct GLST analyses because of lack of intake, cases per strata and personyear information in the articles. 
Meta-analysis of dairy intake and CVD

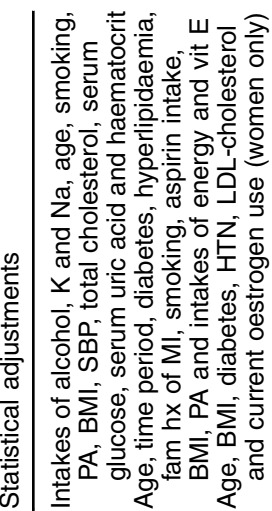

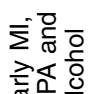

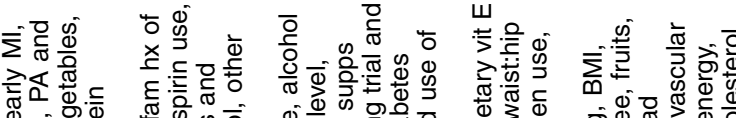

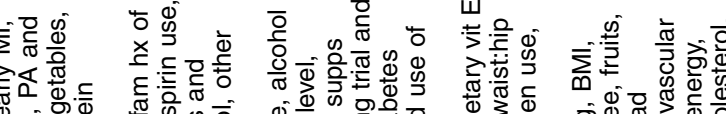

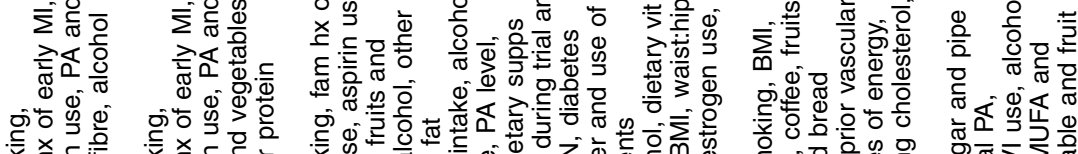

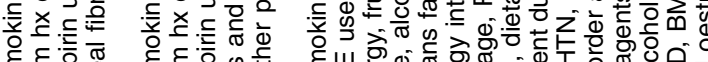

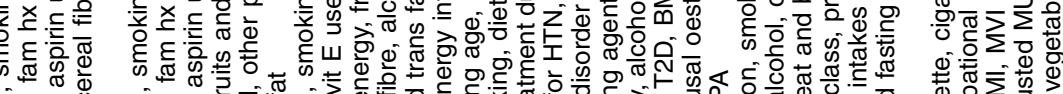

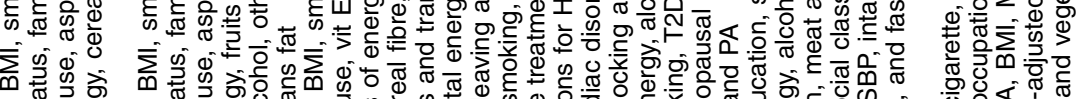
m

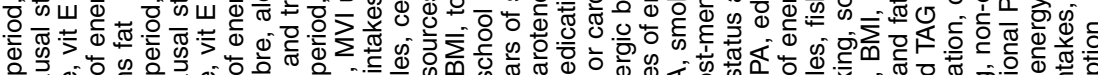

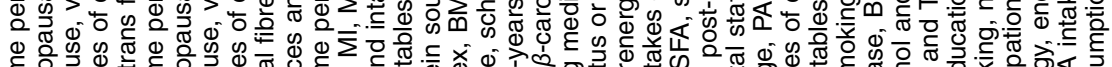

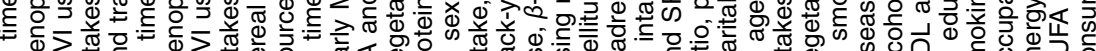
ब

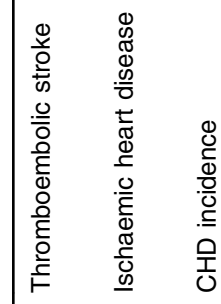

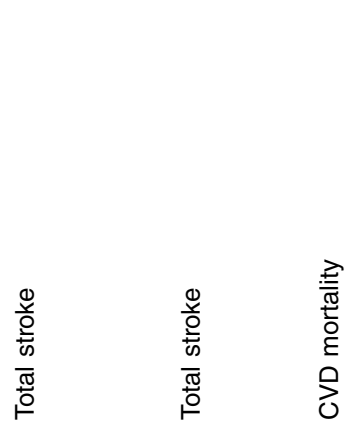

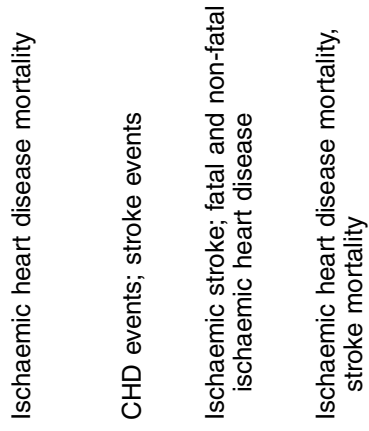
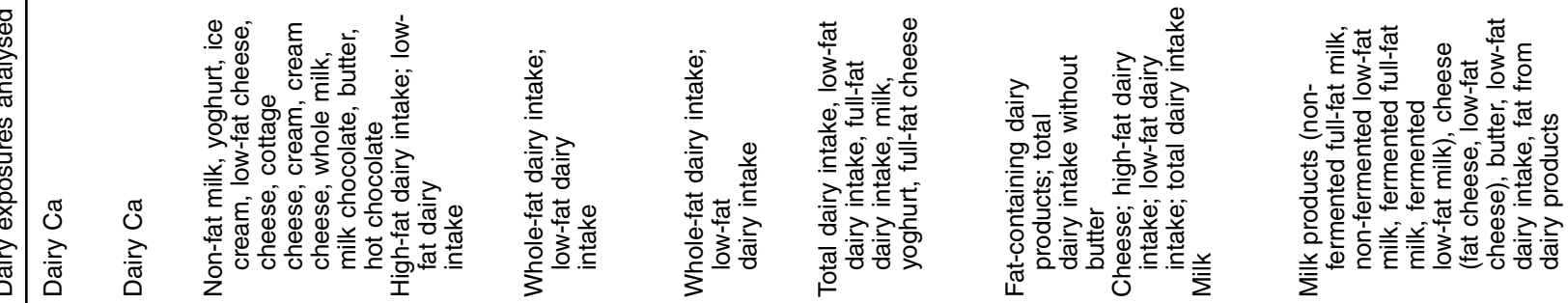

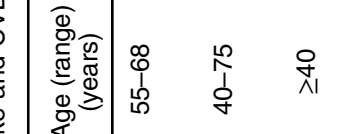

占

占

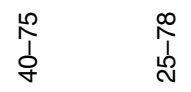

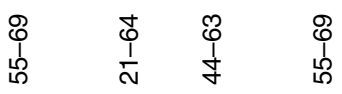

(1)

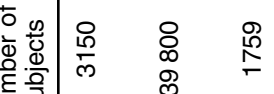

\begin{tabular}{ll}
0 & 0 \\
0 & 0 \\
0 & 0 \\
\hline & 0
\end{tabular}

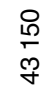

กิ

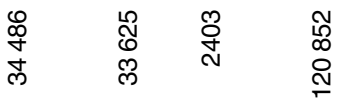

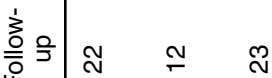

$\stackrel{\circ}{\sim}$

$\stackrel{N}{N}$

ล

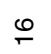

$\infty$

요 우

要

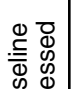

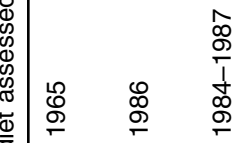

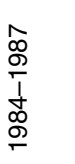

$\begin{array}{ll}\stackrel{\circ}{\circ} & \stackrel{\circ}{\circ} \\ \stackrel{\circ}{\circ} & \stackrel{\circ}{\circ}\end{array}$

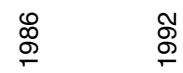

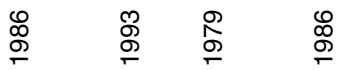

ไฟฝ

空

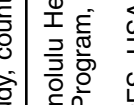

芯

ำ

$\begin{array}{ll}\nwarrow & \frac{\pi}{\omega} \\ 3 & 3 \\ \frac{5}{2} & \frac{5}{1} \\ \frac{1}{2} & \frac{1}{2}\end{array}$

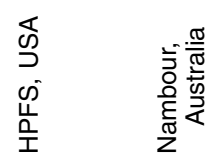

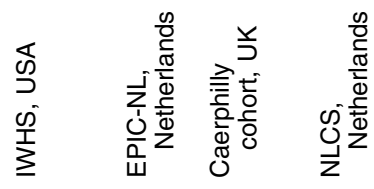

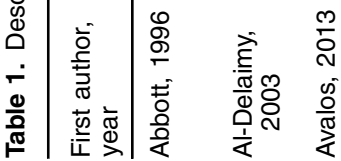

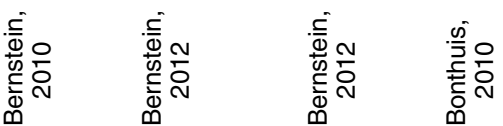

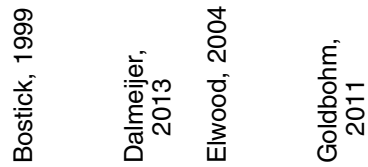




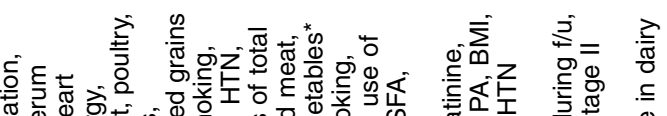

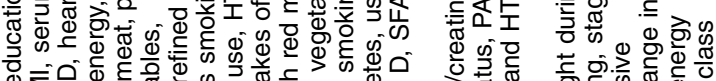

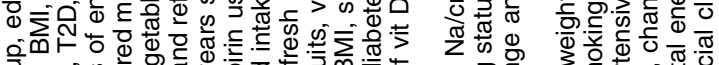

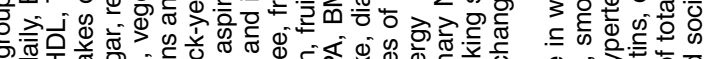

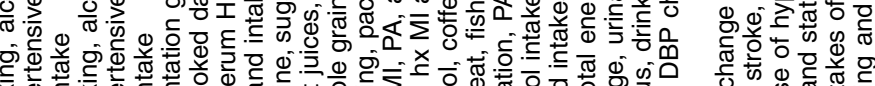
항. ह

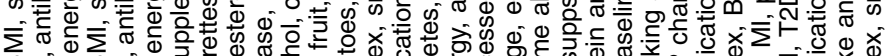
m

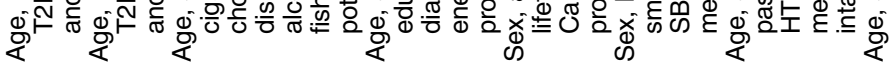
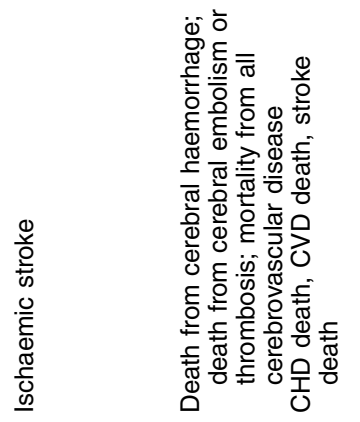

章

率

.

$\frac{\pi}{\overline{0}}$

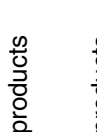

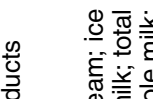

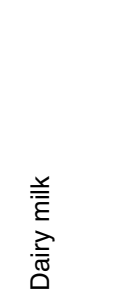

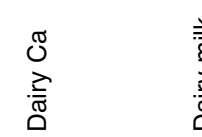

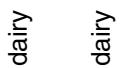

过

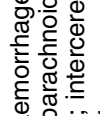

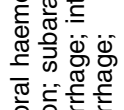

焉.

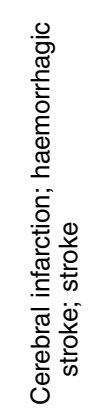

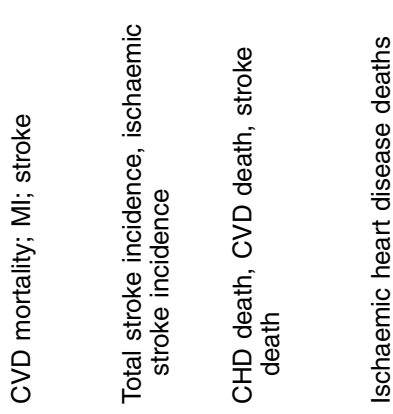

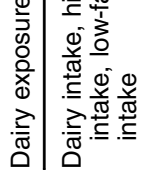

$\begin{array}{lllll}0 & 8 & 0 & 0 \\ 0 & 0 & 0 \\ 0 & 0 & 0 & 0 \\ 0 & & 0 & 0\end{array}$

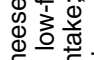

은.

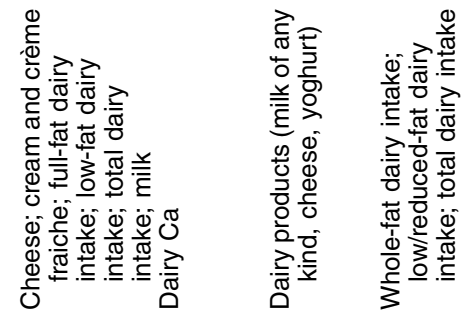

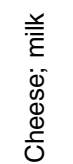

\begin{tabular}{lll}
\hline \\
0 \\
$\infty$ \\
$\infty$
\end{tabular}

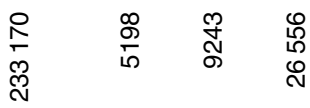

$\overline{8}$
$\stackrel{5}{1}$
$\stackrel{1}{1}$

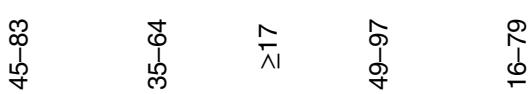

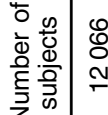

응 ำ ล

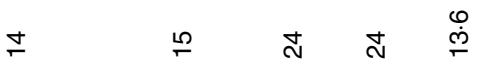

$\stackrel{\text { ำ }}{\stackrel{2}{0}}$

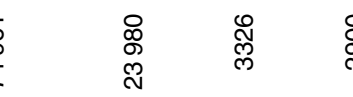

\&

8

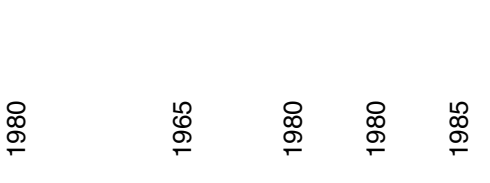

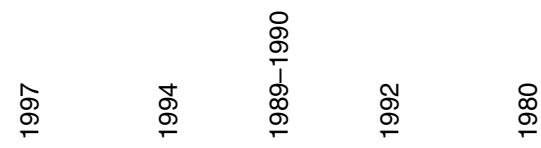

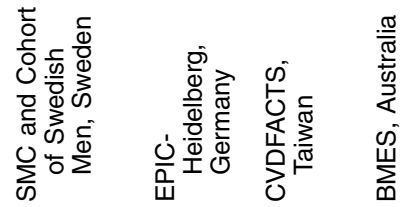

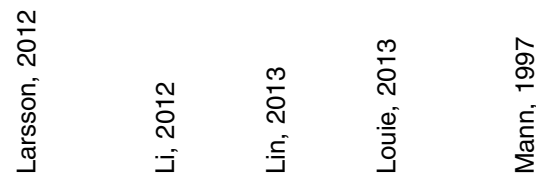


Meta-analysis of dairy intake and CVD
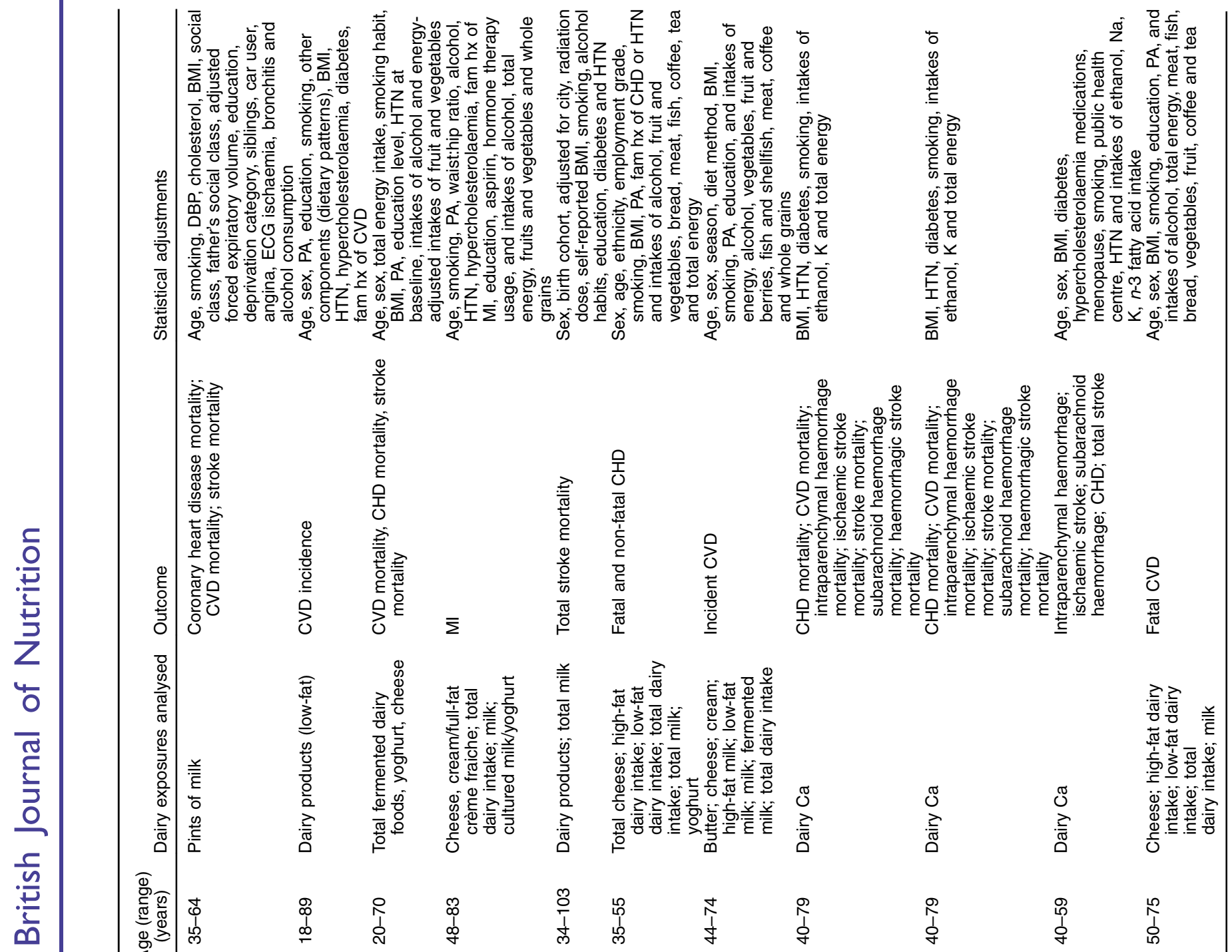

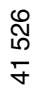

$\stackrel{\circ}{\circ}$

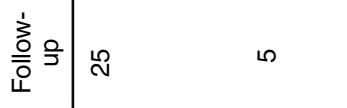

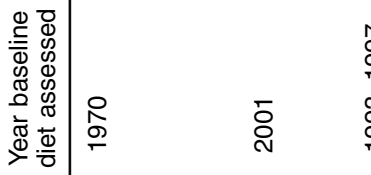

总

总 兽 总

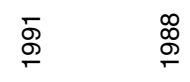

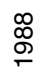

용

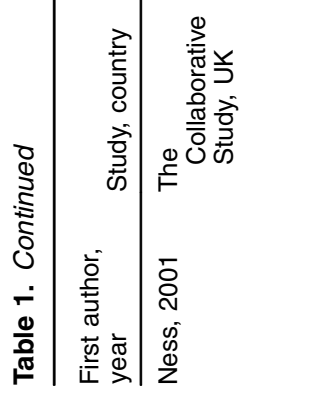

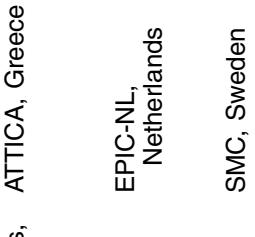

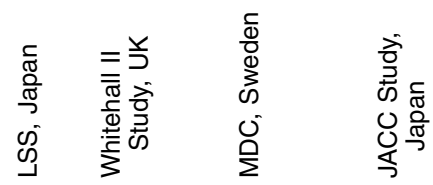

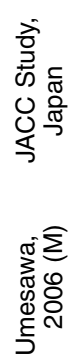

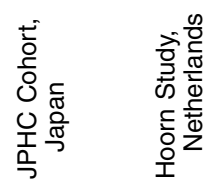

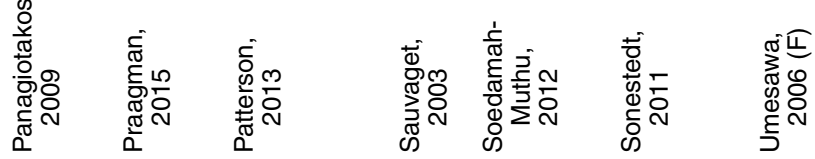

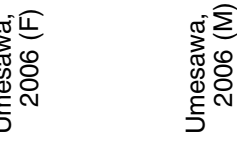

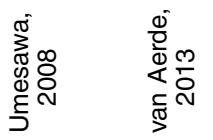


Milk. The summary association between total milk intake and total CVD was $0.94\left(95 \%\right.$ CI $\left.0 \cdot 86,1 \cdot 03, P_{\mathrm{H}}=0.167, I^{2}=38 \cdot 1\right)$, but it was based on only four studies ${ }^{(32,46,51,54)}$. Collectively, milk consumption was not associated with $\mathrm{CHD}$, with summary associations observed slightly above and below the null value across sub-group analyses by country, sex, follow-up duration and dose. Meta-analysis of total milk and total stroke produced a non-statistically significant summary association of $0.90(95 \%$ CI $0.79,1.02)$ with significant heterogeneity $\left(P_{\mathrm{H}}<0.001\right.$, $\left.I^{2}=79 \cdot 6\right)$. The study by Larsson et al. ${ }^{(40)}$ appeared to be an outlier. Removal of this study in a sensitivity analyses resulted in an SRRE of $0.85(95 \% \mathrm{CI} 0.79,0.92)$ and made the model more homogeneous $\left(P_{\mathrm{H}}=0.163, I^{2}=34.7\right)$. Although SRRE were similar and in the inverse direction, the model for total milk and total stroke among study participants followed up more than 15 years was homogeneous $\left(P_{\mathrm{H}}=0 \cdot 780, I^{2}=0 \cdot 0\right)$. No doseresponse relationship between total milk consumption and total stroke was apparent in our categorical intake analyses. Moreover, testing for dose-response using the GLST procedure resulted in no dose-response pattern (RR per serving $=1 \cdot 0$; $95 \%$ CI $0.98,1.02)$, and there was no evidence that using linear splines significantly improved model fit $\left(\chi^{2} P\right.$ value $\left.=0 \cdot 85\right)$.

Cheese. Cheese intake was associated inversely and nonstatistically significantly with total CVD (SRRE $=0.89 ; 95 \%$ CI $0 \cdot 78,1 \cdot 01, P_{\mathrm{H}}=0.317, I^{2}=13.0$ ), but only three studies reported results data for this relationship ${ }^{(23,47,51)}$. Consumption of cheese was associated with a statistically significant inverse SRRE of $0.82(95 \%$ CI $0.72,0.93)$ with minimal heterogeneity $\left(P_{\mathrm{H}}=\right.$ $\left.0 \cdot 639, I^{2}=0 \cdot 0\right)$ for total CHD risk ${ }^{(29,35,47,48,50)}$. Analytical models based on intake categories were all homogeneous, and analyses based on $0-0.5$ servings and $>0.5-1.5$ servings were not statistically significant, whereas $>1.5$ servings of cheese was associated with a statistically significant inverse SRRE of 0.86 ( $95 \% \mathrm{CI} 0.79,0.94)$. In addition, analysis using the GLST procedure resulted in a $2 \%$ (RR per serving $=0.98 ; 95 \%$ CI 0.95 , $1 \cdot 01)$, albeit non-statistically significant, decrease in the RR of CHD for every serving increase of cheese intake after taking covariance into account. However, the use of linear splines did not significantly improve GLST model fit $\left(\chi^{2} P\right.$ value $\left.=0.67\right)$. As with CHD, cheese intake was associated inversely and statistically significantly with total stroke (SRRE $=0.87 ; 95 \%$ CI 0.77 , $\left.0.99, P_{\mathrm{H}}=0.198, I^{2}=33.5\right)^{(35,40,41,47)}$. Although a consistent pattern of intake response was not as clear, statistically significant inverse associations were found for $>0.5-1.5$ servings and for $>1.5$ servings of cheese and total stroke. GLST analyses did not support a significant pattern of association based on linear analyses (RR per serving $=0.99 ; 95 \% \mathrm{CI} 0.97,1.01$ ) or the use of linear splines $\left(\chi^{2} P\right.$ value $\left.=0 \cdot 485\right)$.

Yoghurt. Yoghurt consumption was not associated significantly with CVD or CHD. More studies are needed to evaluate the potential relationship between yoghurt intake and CVD and CVD-related outcomes.

Calcium from dairy products. Ca from dairy sources (as a reported variable in the individual studies) was not associated 
significantly with total CHD (SRRE $=0.94 ; 95 \%$ CI 0.82 $1.08)^{(28,42,52,53)}$, but it was associated with a strong and statistically significant inverse SRRE for total stroke (SRRE $=0.69 ; 95 \%$ CI $\left.0 \cdot 60,0 \cdot 81, P_{\mathrm{H}}=0 \cdot 274, I^{2}=21 \cdot 2\right)^{(27,37,42,52,53)}$. A non-linear pattern of inverse associations for total stroke based on 0-100, 100-300 and $>300 \mathrm{mg}$ of dairy Ca was observed. We were unable to complete a GLST analysis on Ca from dairy product because of a lack of intake, cases per strata and person-year information in the articles.

\section{Discussion}

Because of the significant public health burden of CVD, identifying modifiable factors that may decrease the risk of this disease is of great importance. Thus, we conducted a comprehensive meta-analysis to estimate associations between dairy intake and CVD, CHD and stroke by using all available data from prospective cohort studies. Although based on data from observational studies, our analyses indicate that dairy consumption may be associated inversely with CVD, CHD and stroke, based on extreme quantile comparisons. Collectively, the large majority of summary associations were $<1 \cdot 0$, with many statistically significant inverse associations. Although the summary associations were not overly strong in magnitude (as is commonplace in nutritional epidemiology studies), many analyses produced $5-15 \%$ reductions in CVD, CHD and stroke risk.

On the basis of data from the USDA, the average American consumes approximately 1.85 servings of dairy/d, with men and women over the age of 20 years consuming 1.95 and 1.50 servings, respectively ${ }^{(55)}$. However, the USDA currently recommends an equivalency of three cups of dairy per $\mathrm{d}$, with a focus on fat-free or low-fat milk, yoghurt and cheese. We did not observe clear monotonic inverse trends based on increasing dairy intake and CVD outcomes, but the majority of our stratified intake analyses show that up to three (or above) servings of total dairy intake may be associated inversely with CHD and stroke risk. Similarly, cheese consumption was associated inversely with CHD and stroke risk at all levels of intake, with statistically significant SRRE at $>1.5$ servings. In contrast, no clear or consistent patterns of inverse associations based on frequency of milk intake were apparent, which was partly because of greater data inflection in the individual studies. Our GLST and linear spline analyses did not produce significant inverse dose-response trends based on increasing frequency of dairy intake. Such analyses require studies to report the number of cases and person-years in each intake strata using a proportional hazards modelling structure. As such, our GLST analyses included fewer studies based on limited reporting compared with the stratified intake analyses. However, the GLST modelling accounts for within-study covariance. Additional studies, with more complete data reporting for each dairy intake strata, are needed to more comprehensively examine potential dose-response patterns.

Our results are concordant with previously published metaanalyses of dairy consumption and CVD, CHD and stroke. The most recently published meta-analysis of prospective cohort studies of dairy consumption and CVD reported a summary RR of 0.88 (95\% CI 0.81, 0.96) for dairy consumption and overall risk of $\mathrm{CVD}^{(14)}$, as well as a statistically significant inverse association for stroke ( $\mathrm{RR}=0.87 ; 95 \%$ CI $0 \cdot 77,0 \cdot 99)$. However, the authors did not perform any dose-responses analyses, and used broader categories of dairy variables and outcome variables in their analyses. Because broad categories of dairy variables were used (e.g. milk included with total dairy intake) in their analyses, a larger number of studies were included in their analytical models. In contrast, our analyses were rigorously specific to the type of dairy variable in that we did not combine different types of dairy products unless a composite dairy variable was reported in a study. Despite these methodological differences, our summary findings were relatively consistent.

There are several potential mechanisms by which dairy intake may beneficially have a role in CVD risk reduction. Dairy products are a rich source of (i) minerals, such as $\mathrm{Ca}, \mathrm{K}$ and $\mathrm{Mg}$; (ii) vitamins, such as riboflavin and vitamin $\mathrm{B}_{12}$; and (iii) protein, such as whey and casein ${ }^{(56)}$. Individually, collectively or interactively, all of these nutrient sources may have a favourable effect on CVD. The potential role of $\mathrm{Ca}$ intake and supplementation on CVD risk is a controversial topic, with some studies suggesting an increased risk while other studies indicating a null or decreased risk ${ }^{(57-59)}$. However, the source of Ca may be important.

Although the epidemiological evidence appears to support a beneficial role of dairy intake on CVD and other chronic disease outcomes, some researchers have suggested that consumption of dairy products, a source of SFA, may contribute to an increase in heart disease. Experimental evidence from human studies have shown that high intake of SFA increases plasma levels of LDL-cholesterol ${ }^{(60,61)}$, although milk and dairy products have also been associated with an increase in HDLcholesterol and blood pressure reduction ${ }^{(11,61-64)}$. Indeed, the potential role of diets that are high in SFA on CVD risk is unclear and controversial, although emerging science suggests that a potential role of SFA on CVD risk may not be merited. Risk may depend on the substitutions for SFA that occur as different foods may affect risk in variable ways ${ }^{(56,65-68)}$. In a meta-analysis of prospective cohort studies, intake of SFA was not associated with an increased risk of CHD ( $\mathrm{RR}=1 \cdot 07$; $95 \%$ CI 0.96, 1.19), stroke $(\mathrm{RR}=0.81 ; 95 \% \mathrm{CI} 0.62,1.05)$ or CVD (RR $=1.00 ; 95 \%$ CI $0.89,1.11)$ based on comparisons of extreme quintiles ${ }^{(68)}$.

Although our analytical models were harmonised based on similar exposure and similar outcome classifications, the data used in this meta-analysis were generated from observational studies. Therefore, the validity of a meta-analysis is not immune to limitations, particularly in nutritional epidemiology where information bias is a predominant concern. In an effort to garner a better understanding of any potential relationships between dairy products and CVD, CHD and stroke, we conducted a variety of unique meta-analyses to discern any potential patterns of associations. Although most analyses produced inverse associations, it may be possible that those who consume dairy products, particularly low-fat dairy intake, may engage in other favourable dietary and lifestyle habits. However, our analyses of full-fat dairy intake and cheese were not associated with positive associations for CVD. Rather, inverse associations were 


\begin{tabular}{|c|c|c|c|c|c|c|c|c|c|c|c|c|}
\hline $\begin{array}{l}0 \\
\stackrel{0}{0} \\
2 \\
z\end{array}$ & 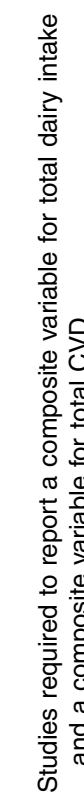 & 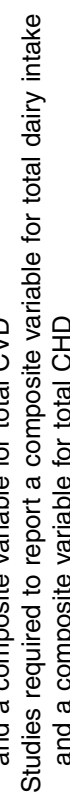 & 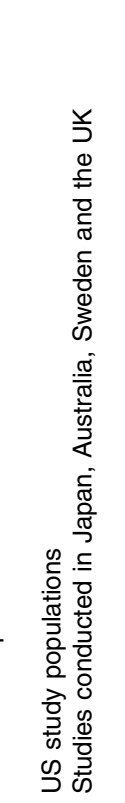 & 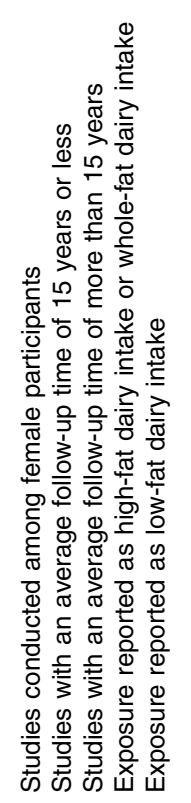 & 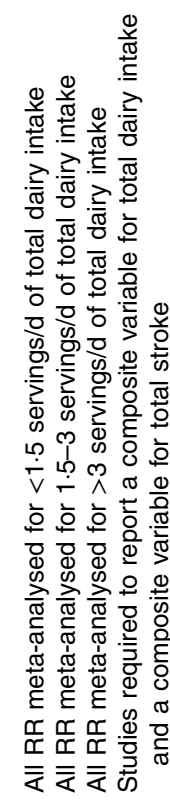 & 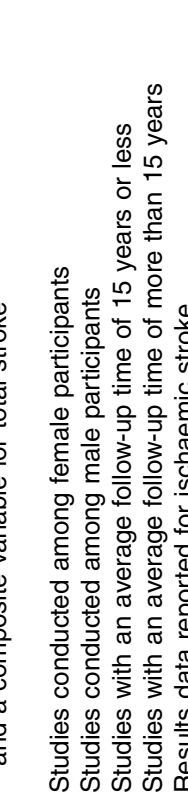 & 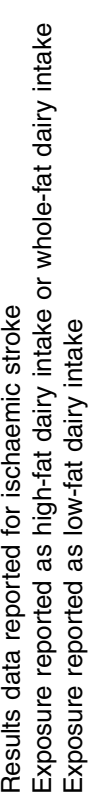 & 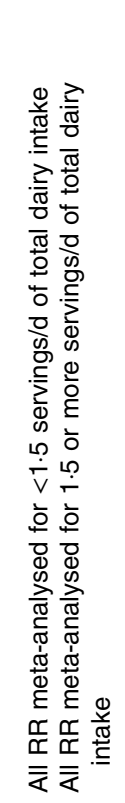 & 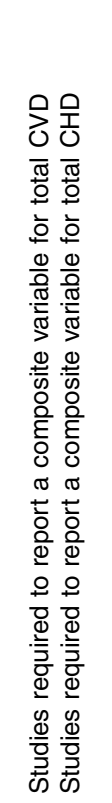 & 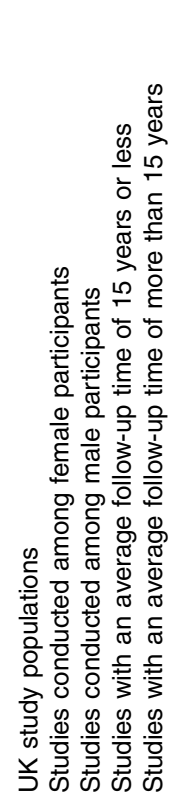 & 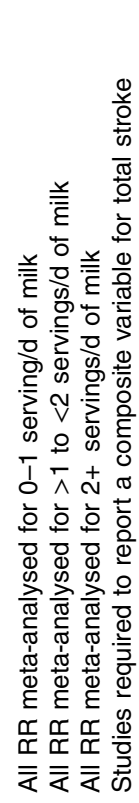 & 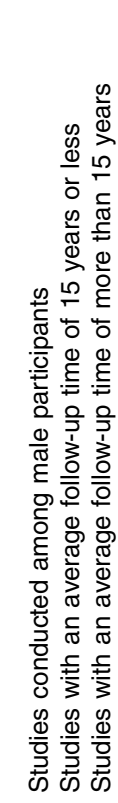 \\
\hline $\begin{array}{l}N \\
\cdots \\
a^{\underline{I}}\end{array}$ & $\begin{array}{l}\stackrel{\circ}{\Lambda} \\
\hat{\sim} \\
0 \\
0 \\
0 \\
0 \\
0\end{array}$ & 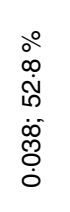 & 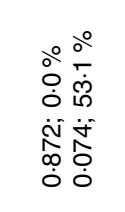 & 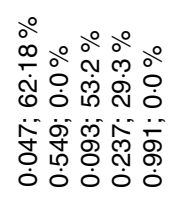 & 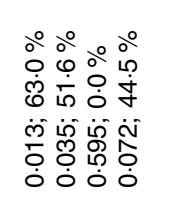 & 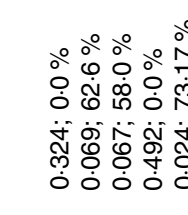 & 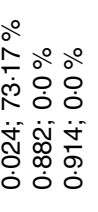 & 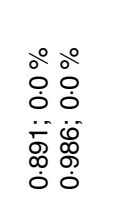 & 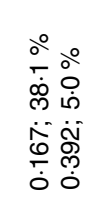 & 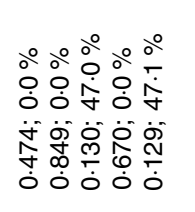 & 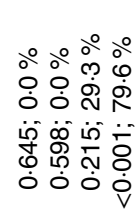 & 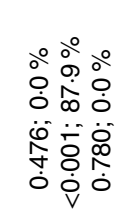 \\
\hline $\begin{array}{l}\overline{0} \\
\circ \\
i \\
\circ\end{array}$ & $\begin{array}{l}\stackrel{+}{0} \\
\dot{+} \\
\dot{0} \\
\dot{0}\end{array}$ & $\begin{array}{l}\dot{+} \\
\dot{\vdots} \\
\dot{0} \\
\dot{0}\end{array}$ & 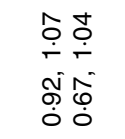 & 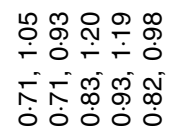 & 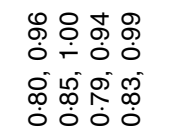 & 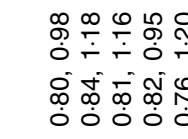 & 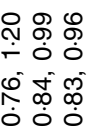 & $\begin{array}{ll}0 & 0 \\
\circ & \wp \\
0 & 0 \\
0 & 0 \\
0 & 0 \\
0 & 0\end{array}$ & 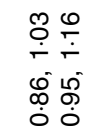 & 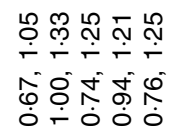 & 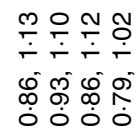 & 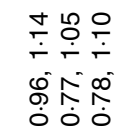 \\
\hline 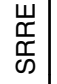 & $\begin{array}{l}\infty \\
\infty \\
0\end{array}$ & б. & 兽 & 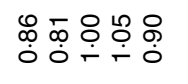 & 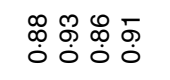 & 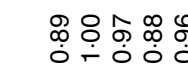 & ஜ & ๙ू. & 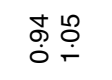 & 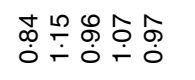 & 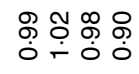 & 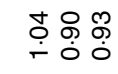 \\
\hline $\begin{array}{l}\overline{0} \\
\frac{\mathrm{d}}{\mathrm{O}} \\
\end{array}$ & 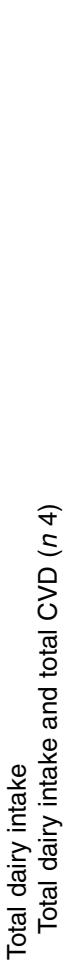 & 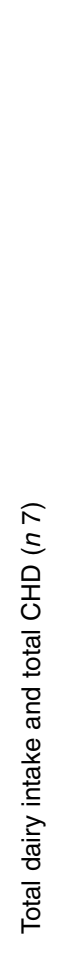 & 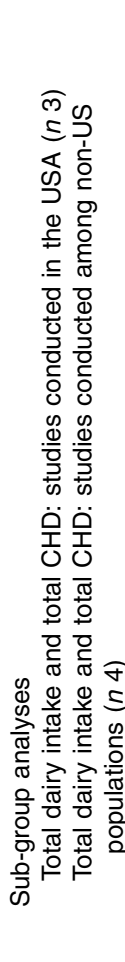 & 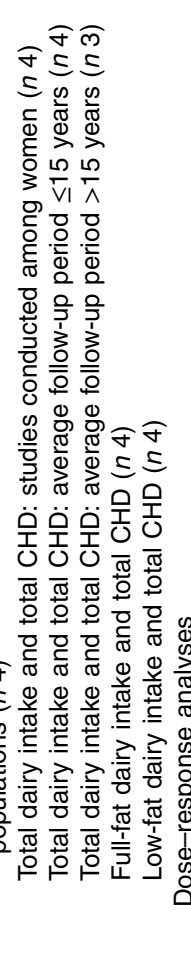 & 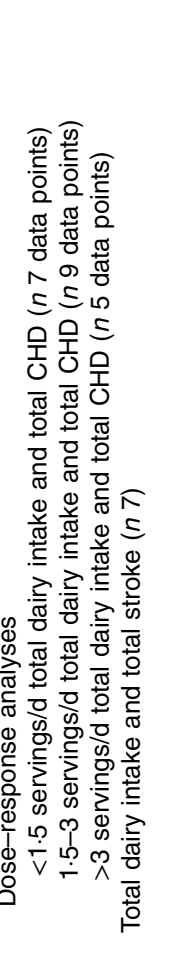 & 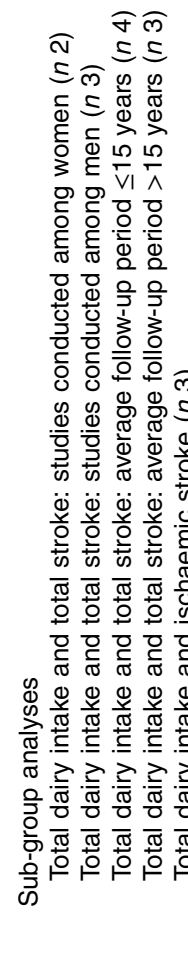 & 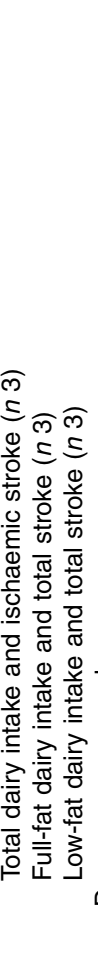 & 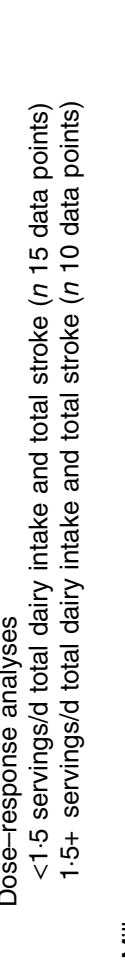 & 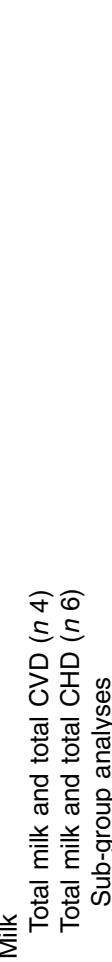 & 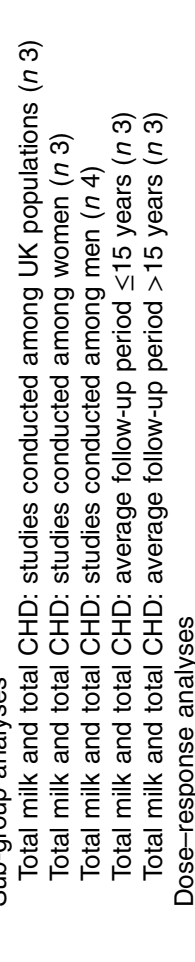 & 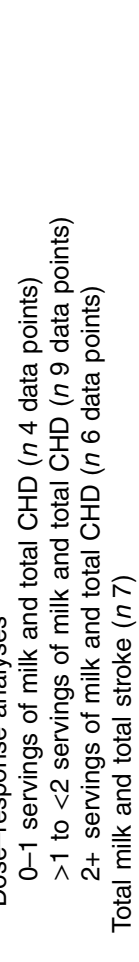 & 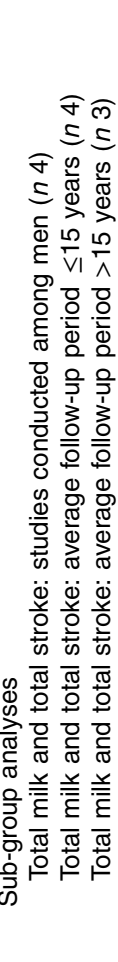 \\
\hline
\end{tabular}


Meta-analysis of dairy intake and CVD

응옹

흐흥ㅎㅎㅎㅎㅎㅎㅁ

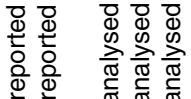

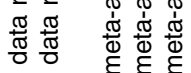

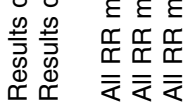

$\frac{8}{3} \frac{0}{0}$

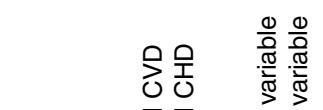

$+$

D.

ه

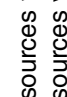

造过

$\frac{10}{2}$

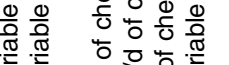

离

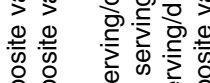

흥 홍ㅎㅁ

क्षे

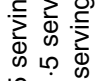

ह

น

닝ำ

ब

눙흥 훟ㅎㅎㅎㅎㅎㅎㅇ 흫ㅎㅎㅎㅎ

送迹

o 8

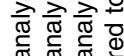

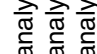

흥.

要需恋

है ह

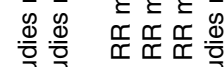

$\underset{\frac{\pi}{x}}{\frac{\pi}{x}} \frac{\pi}{\mathbb{x}}$

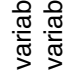

迹

की

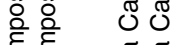

$\varepsilon$ 을

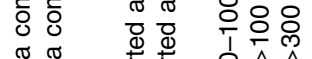

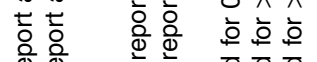

잉

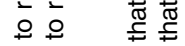

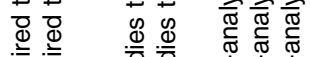

言言

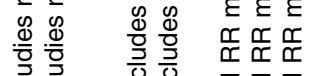

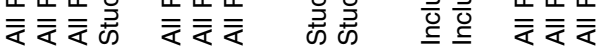

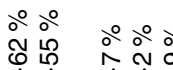

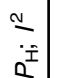

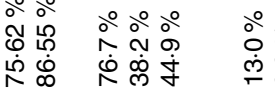

$\stackrel{\circ}{\circ} \circ$

웅ㅇํㅇำ

ㅇํㅇㅇำ

ㅇำ

$\circ \circ \circ \circ$

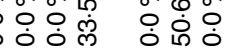

幽方

ठํㅇㅇ

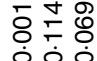

다유

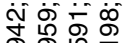

iि

苇过

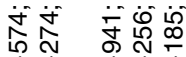

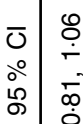

융 누ㅇㅠㅜ

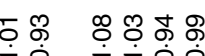

o o o

क்

00

o

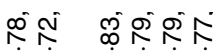

숭ํㅇํ.

$\stackrel{\sim}{\sim} \stackrel{\infty}{\stackrel{\infty}{\sim}}$

ஜํํㅇ 웅숭

o: 0 o

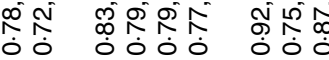

कृ

ฌ

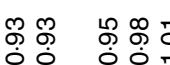

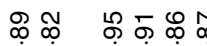

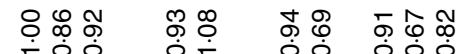




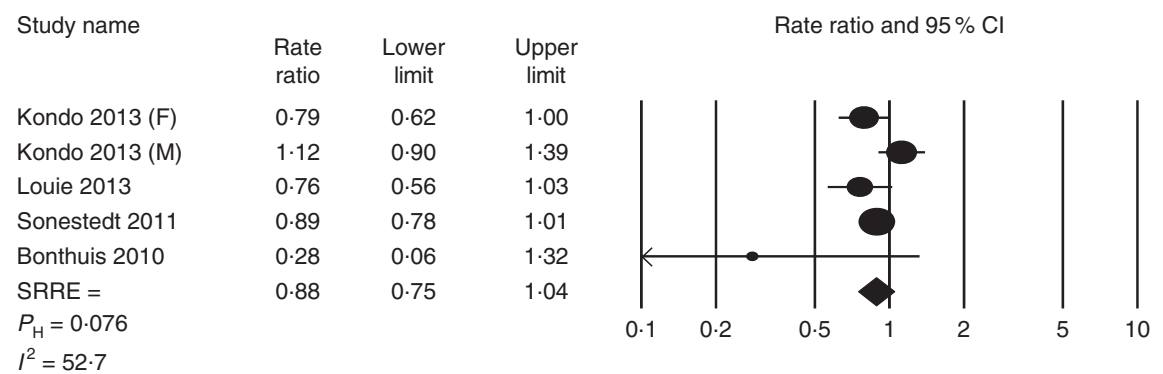

Fig. 2. Meta-analysis of total dairy intake and total CVD (high $v$. low intake analysis). SRRE, summary relative risk estimate. Individual studies required to report a composite total dairy variable and a compositive total CVD variable. $F$, female; $M$, male.

$\begin{array}{lccc}\text { Study name } & \begin{array}{c}\text { Rate } \\ \text { ratio }\end{array} & \begin{array}{c}\text { Lower } \\ \text { limit }\end{array} & \begin{array}{c}\text { Upper } \\ \text { limit }\end{array} \\ \text { Bernstein 2010 } & 0.99 & 0.91 & 1.08 \\ \text { Bostick 1999 } & 0.94 & 0.66 & 1.34 \\ \text { Haring 2014 } & 1.04 & 0.84 & 1.29 \\ \text { Kondo 2013 (F) } & 0.60 & 0.36 & 1.00 \\ \text { Kondo 2013 (M) } & 1.49 & 0.91 & 2.45 \\ \text { Louie 2013 } & 0.71 & 0.51 & 0.99 \\ \text { Patterson 2013 } & 0.77 & 0.63 & 0.95 \\ \text { Soedamah-Muthu 2012 } & 0.91 & 0.68 & 1.22 \\ \text { SRRE }= & 0.91 & 0.80 & 1.04 \\ P_{\mathrm{H}}=0.038 & & & \\ I^{2}=52.8 & & & \end{array}$

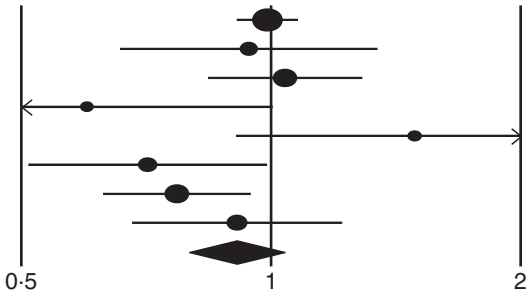

Fig. 3. Meta-analysis of total dairy intake and total $\mathrm{CHD}$ (high $v$. low intake analysis). SRRE, summary relative risk estimate. Individual studies required to report a composite total dairy variable and a compositive total $\mathrm{CHD}$ variable. $\mathrm{F}$, female; $\mathrm{M}$, male.

$\begin{array}{lccc}\text { Study name } & \begin{array}{c}\text { Rate } \\ \text { ratio }\end{array} & \begin{array}{c}\text { Lower } \\ \text { limit }\end{array} & \begin{array}{c}\text { Upper } \\ \text { limit }\end{array} \\ \text { Bernstein 2012 (F) } & 0.90 & 0.81 & 1.00 \\ \text { Bernstein 2012 (M) } & 0.91 & 0.79 & 1.04 \\ \text { Kondo 2013 (F) } & 0.75 & 0.53 & 1.06 \\ \text { Kondo 2013 (M) } & 0.91 & 0.67 & 1.24 \\ \text { Larsson 2009 (ischaemic) } & 1.14 & 0.99 & 1.32 \\ \text { Larsson 2012 } & 0.91 & 0.80 & 1.03 \\ \text { Louie 2013 } & 0.98 & 0.57 & 1.68 \\ \text { Sauvaget 2003 } & 0.73 & 0.57 & 0.94 \\ \text { Lin 2013 } & 0.74 & 0.48 & 1.14 \\ \text { SRRE = } & 0.91 & 0.83 & 0.99\end{array}$

SRRE =

$P_{\mathrm{H}}=0.324$

$83 \quad 0.99$

$I^{2}=0.0$

Removal of Larsson 2009 in a sensitivity analyses resulted in and SRRE of $0.88(95 \% \mathrm{Cl} 0.83,-0.94)$ with no heterogeneity $\left(P_{\mathrm{H}}=0.73, I^{2}=0.00\right)$

Fig. 4. Meta-analysis of total dairy intake and total stroke. SRRE, summary relative risk estimate. Individual studies required to report a composite total dairy variable and a compositive total stroke variable. F, female; M, male.

generally observed for these dietary variables. Furthermore, most of the observational studies included in this analysis adjusted for dietary and lifestyle factors, such as physical activity, sedentary lifestyle and hypertension.

\section{Conclusions}

Future prospective studies of dairy consumption and CVD should focus on isolating the independent effects of specific types of dairy products on specific CVD outcomes while clearly indicating the intake levels per stratum. In addition, reporting RR by varying levels of statistical adjustment may further elucidate the relevant potential confounding factors on dairy intake and CVD, and may help researchers estimate more accurately the independent effects of dairy intake. The current meta-analysis serves as an update and expansion to the existing body of literature on this topic. The results of this meta-analysis have shown that dairy consumption (high $v$. low intake) may be associated with reduced risks of CVD, CHD and stroke, although a dose-response relationship is not clear based on the existing evidence. Additional studies are needed that model dairy intake as a continuous variable to provide a better understanding of any potential dose-response patterns. As future studies are published, new meta-analyses may be warranted to continually refine our understanding of the relationship between dairy intake and CVD. 


\section{Acknowledgements}

This research was supported by the Dairy Research Institute (DRI).

The following authors contributed to this paper in the following ways.

D. D. A. conceptualised the analytical protocol, conducted the analyses and was the primary writer. A. J. V. conducted dose-response analyses, created figures and reviewed the content of the manuscript. L. C. B., P. E. M., S. R. I., and M. M. reviewed the content of the manuscript, provided editorial feedback, conducted the literature search, assisted with table and figure creation and extracted data. H. W. and A. D. reviewed the content of the manuscript and provided statistical support. S. S. C. and J. P. F. reviewed the content of the manuscript and provided editorial feedback.

The authors declare that they have no conflicts of interest. DRI did not influence the data selection, interpretation or the decision on how or what to publish.

\section{References}

1. World Health Organization (2011) Global Status Report on Noncommunicable Diseases 2010. Geneva: WHO.

2. Nichols M, Townsend N, Luengo-Fernandez R, et al. (2012) European Cardiovascular Disease Statistics 2012. Brussels and Sophia Antipolis: European Heart Network and European Society of Cardiology.

3. Go AS, Mozaffarian D, Roger VL, et al. (2014) Executive summary: heart disease and stroke statistics - 2014 update: a report from the American Heart Association. Circulation 129, 399-410.

4. Go AS, Mozaffarian D, Roger VL, et al. (2014) Heart disease and stroke statistics - 2014 update: a report from the American Heart Association. Circulation 129, e28-e292.

5. Kochanek KD, Xu JQ, Murphy SL, et al. (2011) Deaths: final data for 2009. National vital statistics reports, 29 December. Hyattsville, MD: US Department of Health and Human Services, Centers for Disease Control and Prevention.

6. Murphy SL, Xu JQ \& Kochanek KD (2013) Deaths: final data for 2010. Nationtal vital statistics report, 8 May. Hyattsville, MD: US Department of Health and Human Services, Centers for Disease Control and Prevention.

7. Yang Q, Cogswell ME, Flanders WD, et al. (2012) Trends in cardiovascular health metrics and associations with allcause and CVD mortality among US adults. JAMA 307, $1273-1283$.

8. Lackland DT, Roccella EJ, Deutsch AF, et al. (2014) Factors influencing the decline in stroke mortality: a statement from the American Heart Association/American Stroke Association. Stroke 45, 315-353.

9. Soedamah-Muthu SS, Ding EL, Al-Delaimy WK, et al. (2011) Milk and dairy consumption and incidence of cardiovascular diseases and all-cause mortality: dose-response meta-analysis of prospective cohort studies. Am J Clin Nutr 93, 158-171.

10. Soedamah-Muthu SS, Verberne LD, Ding EL, et al. (2012) Dairy consumption and incidence of hypertension: a doseresponse meta-analysis of prospective cohort studies. Hypertension 60, 1131-1137.

11. Elwood PC, Pickering JE, Givens DI, et al. (2010) The consumption of milk and dairy foods and the incidence of vascular disease and diabetes: an overview of the evidence. Lipids 45, 925-939.
12. Hu D, Huang J, Wang Y, et al. (2014) Dairy foods and risk of stroke: a meta-analysis of prospective cohort studies. Nutr Metab Cardiovasc Dis 24, 460-469.

13. Larsson SC, Orsini N \& Wolk A (2013) Dietary calcium intake and risk of stroke: a dose-response meta-analysis. Am J Clin Nutr 97, 951-957.

14. Qin LQ, Xu JY, Han SF, et al. (2015) Dairy consumption and risk of cardiovascular disease: an updated meta-analysis of prospective cohort studies. Asia Pac J Clin Nutr 24, 90-100.

15. Moher D, Liberati A, Tetzlaff J, et al. (2009) Preferred reporting items for systematic reviews and meta-analyses: the PRISMA statement. PLoS Med 6, e1000097.

16. DerSimonian R \& Laird N (1986) Meta-analysis in clinical trials. Control Clin Trials 7, 177-188.

17. Aune D, Chan DS, Lau R, et al. (2011) Dietary fibre, whole grains, and risk of colorectal cancer: systematic review and doseresponse meta-analysis of prospective studies. BMJ 343, 20.

18. Greenland S \& Longnecker MP (1992) Methods for trend estimation from summarized dose-response data, with applications to meta-analysis. Am J Epidemiol 135, 1301-1309.

19. Orsini N, Li R, Wolk A, et al. (2012) Meta-analysis for linear and nonlinear dose-response relations: examples, an evaluation of approximations, and software. Am J Epidemiol 175, 66-73.

20. Orsini N, Bellocco R \& Greenland S (2006) Generalized least squares for trend estimation of summarized doseresponse data. Stata J $\mathbf{6}, 40-57$.

21. United States Department of Agriculture (2011) National Nutrient Database for Standard Reference. http://ndb nal usda gov/ (accessed May 2015).

22. Dalmeijer GW, Struijk EA, van der Schouw YT, et al. (2013) Dairy intake and coronary heart disease or stroke - a population-based cohort study. Int J Cardiol 167, 925-929.

23. van Aerde MA, Soedamah-Muthu SS, Geleijnse JM, et al. (2013) Dairy intake in relation to cardiovascular disease mortality and all-cause mortality: the Hoorn Study. Eur J Nutr 52, 609-616.

24. Panagiotakos DB, Pitsavos C, Chrysohoou C, et al. (2009) Prevalence and five-year incidence (2001-2006) of cardiovascular disease risk factors in a Greek sample: the ATTICA study. Hellenic J Cardiol 50, 388-395.

25. Higgins JP \& Thompson SG (2002) Quantifying heterogeneity in a meta-analysis. Stat Med 21, 1539-1558.

26. Rothstein H, Sutton A \& Borenstein M (2005) Publication Bias in Meta-Analysis: Prevention, Assessment, and Adjustments. Chichester: John Wiley and Sons Ltd.

27. Abbott RD, Curb JD, Rodriguez BL, et al. (1996) Effect of dietary calcium and milk consumption on risk of thromboembolic stroke in older middle-aged men. The Honolulu Heart Program. Stroke 27, 813-818.

28. Al-Delaimy WK, Rimm E, Willett WC, et al. (2003) A prospective study of calcium intake from diet and supplements and risk of ischemic heart disease among men. Am J Clin Nutr 77, 814-818.

29. Avalos EE, Barrett-Connor E, Kritz-Silverstein D, et al. (2013) Is dairy product consumption associated with the incidence of CHD? Public Health Nutr 16, 2055-2063.

30. Bernstein AM, Sun Q, Hu FB, et al. (2010) Major dietary protein sources and risk of coronary heart disease in women. Circulation 122, 876-883.

31. Bernstein AM, Pan A, Rexrode KM, et al. (2012) Dietary protein sources and the risk of stroke in men and women. Stroke 43, 637-644.

32. Bonthuis M, Hughes MC, Ibiebele TI, et al. (2010) Dairy consumption and patterns of mortality of Australian adults. Eur J Clin Nutr 64, 569-577. 
33. Bostick RM, Kushi LH, Wu Y, et al. (1999) Relation of calcium, vitamin $\mathrm{D}$, and dairy food intake to ischemic heart disease mortality among postmenopausal women. Am J Epidemiol 149, 151-161.

34. Elwood PC, Pickering JE, Fehily AM, et al. (2004) Milk drinking, ischaemic heart disease and ischaemic stroke I. Evidence from the Caerphilly cohort. Eur J Clin Nutr $\mathbf{5 8}$, 711-717.

35. Goldbohm RA, Chorus AM, Galindo GF, et al. (2011) Dairy consumption and 10-y total and cardiovascular mortality: a prospective cohort study in the Netherlands. Am J Clin Nutr 93, 615-627.

36. Haring B, Gronroos N, Nettleton JA, et al. (2014) Dietary protein intake and coronary heart disease in a large community based cohort: results from the Atherosclerosis Risk in Communities (ARIC) Study. PLOS ONE 9, e109552.

37. Iso H, Stampfer MJ, Manson JE, et al. (1999) Prospective study of calcium, potassium, and magnesium intake and risk of stroke in women. Stroke 30, 1772-1779.

38. Kinjo Y, Beral V, Akiba S, et al. (1999) Possible protective effect of milk, meat and fish for cerebrovascular disease mortality in Japan. J Epidemiol 9, 268-274.

39. Kondo I, Ojima T, Nakamura M, et al. (2013) Consumption of dairy products and death from cardiovascular disease in the Japanese general population: the NIPPON DATA80. J Epidemiol 23, 47-54.

40. Larsson SC, Mannisto S, Virtanen MJ, et al. (2009) Dairy foods and risk of stroke. Epidemiology 20, 355-360.

41. Larsson SC, Virtamo J \& Wolk A (2012) Dairy consumption and risk of stroke in Swedish women and men. Stroke $\mathbf{4 3}$, 1775-1780.

42. Li K, Kaaks R, Linseisen J, et al. (2012) Associations of dietary calcium intake and calcium supplementation with myocardial infarction and stroke risk and overall cardiovascular mortality in the Heidelberg cohort of the European Prospective Investigation into Cancer and Nutrition study (EPIC-Heidelberg). Heart 98, 920-925.

43. Lin PH, Yeh WT, Svetkey LP, et al. (2013) Dietary intakes consistent with the DASH dietary pattern reduce blood pressure increase with age and risk for stroke in a Chinese population. Asia Pac J Clin Nutr 22, 482-491.

44. Louie JC, Flood VM, Burlutsky G, et al. (2013) Dairy consumption and the risk of 15-year cardiovascular disease mortality in a cohort of older Australians. Nutrients 5, 441-454.

45. Mann JI, Appleby PN, Key TJ, et al. (1997) Dietary determinants of ischaemic heart disease in health conscious individuals. Heart 78, 450-455.

46. Ness AR, Smith GD \& Hart C (2001) Milk, coronary heart disease and mortality. I Epidemiol Community Health 55 , 379-382.

47. Praagman J, Dalmeijer GW, van der Schouw YT, et al. (2015) The relationship between fermented food intake and mortality risk in the European Prospective Investigation into Cancer and Nutrition-Netherlands cohort. Br J Nutr 113, 498-506.

48. Patterson E, Larsson SC, Wolk A, et al. (2013) Association between dairy food consumption and risk of myocardial infarction in women differs by type of dairy food. J Nutr $\mathbf{1 4 3}$, 74-79.

49. Sauvaget C, Nagano J, Allen N, et al. (2003) Intake of animal products and stroke mortality in the Hiroshima/Nagasaki Life Span Study. Int J Epidemiol 32, 536-543.

50. Soedamah-Muthu SS, Masset G, Verberne L, et al. (2013) Consumption of dairy products and associations with incident diabetes, CHD and mortality in the Whitehall II study. Br J Nutr 109, 718-726.
51. Sonestedt E, Wirfalt E, Wallstrom P, et al. (2011) Dairy products and its association with incidence of cardiovascular disease: the Malmo diet and cancer cohort. Eur J Epidemiol 26, 609-618.

52. Umesawa M, Iso H, Date C, et al. (2006) Dietary intake of calcium in relation to mortality from cardiovascular disease: the JACC Study. Stroke 37, 20-26.

53. Umesawa M, Iso H, Ishihara J, et al. (2008) Dietary calcium intake and risks of stroke, its subtypes, and coronary heart disease in Japanese: the JPHC Study Cohort I. Stroke 39, 2449-2456.

54. Wang C, Yatsuya H, Tamakoshi K, et al. (2015) Milk drinking and mortality: findings from the Japan collaborative cohort study. J Epidemiol 25, 66-73.

55. United States Department of Agriculture (2013) What we eat in America, NHANES 2009-2010, individuals 2 years and over (excluding breast-fed children), day 1 dietary intake data, weighted. Food Patterns Equivalents Database (FPED) 2009-2010. Beltsville, MD: USDA.

56. Soedamah-Muthu SS, Ding EL, Al-Delaimy WK, et al. (2011) Milk and dairy consumption and incidence of cardiovascular diseases and all-cause mortality: dose-response meta-analysis of prospective cohort studies. Am J Clin Nutr 93, 158-171.

57. Wang L, Manson JE \& Sesso HD (2012) Calcium intake and risk of cardiovascular disease: a review of prospective studies and randomized clinical trials. Am J Cardiovasc Drugs 12, $105-116$.

58. Rautiainen S, Wang L, Manson JE, et al. (2013) The role of calcium in the prevention of cardiovascular disease - a review of observational studies and randomized clinical trials. Curr Atheroscler Rep 15, 362.

59. Heaney RP, Kopecky S, Maki KC, et al. (2012) A review of calcium supplements and cardiovascular disease risk. Adv Nutr 3, 763-771.

60. Huth PJ \& Park KM (2012) Influence of dairy product and milk fat consumption on cardiovascular disease risk: a review of the evidence. Adv Nutr 3, 266-285.

61. Mensink RP, Zock PL, Kester AD, et al. (2003) Effects of dietary fatty acids and carbohydrates on the ratio of serum total to HDL cholesterol and on serum lipids and apolipoproteins: a meta-analysis of 60 controlled trials. Am J Clin Nutr 77, 1146-1155.

62. Garcia-Palmieri MR, Costas R Jr, Cruz-Vidal M, et al. (1984) Milk consumption, calcium intake, and decreased hypertension in Puerto Rico. Puerto Rico Heart Health Program study. Hypertension 6, 322-328.

63. Griffith LE, Guyatt GH, Cook RJ, et al. (1999) The influence of dietary and nondietary calcium supplementation on blood pressure: an updated metaanalysis of randomized controlled trials. Am J Hypertens 12, Pt 1, 84-92.

64. Temme EH, Mensink RP \& Hornstra G (1996) Comparison of the effects of diets enriched in lauric, palmitic, or oleic acids on serum lipids and lipoproteins in healthy women and men. Am J Clin Nutr 63, 897-903.

65. Katan MB, Brouwer IA, Clarke R, et al. (2010) Saturated fat and heart disease. Am J Clin Nutr 92, 459-460.

66. Kratz M, Baars T \& Guyenet S (2013) The relationship between high-fat dairy consumption and obesity, cardiovascular, and metabolic disease. Eur J Nutr 52, 1-24.

67. de Oliveira Otto MC, Mozaffarian D, Kromhout D, et al. (2012) Dietary intake of saturated fat by food source and incident cardiovascular disease: the Multi-Ethnic Study of Atherosclerosis. Am J Clin Nutr 96, 397-404.

68. Siri-Tarino PW, Sun Q, Hu FB, et al. (2010) Meta-analysis of prospective cohort studies evaluating the association of saturated fat with cardiovascular disease. Am J Clin Nutr 91 , 535-546. 